LAWRENCE LIVERMORE NATIONAL LABORATORY
Lawrence Livermore National Laboratory Probabilistic Seismic Hazard Codes Validation

J. B. Savy

September 8, 2003 
UCRL-ID-XXXXXX

\section{Lawrence Livermore National Laboratory Probabilistic Seismic Hazard Codes Validation}

Prepared by

J. B. Savy

September 8, 2003

Prepared for

Division of Research Engineering and Safety Office of Nuclear Regulatory Research U.S. Nuclear Regulatory Commission Washington, DC 20555 


\section{DISCLAIMER}

This document was prepared as an account of work sponsored by an agency of the United States Government. Neither the United States Government nor the University of California, nor any of their employees, makes any warranty, express or implied, or assumes any legal liability or responsibility for the accuracy, completeness, or usefulness of any information, apparatus, product, or process disclosed, or represents that its use would not infringe privately owned rights. Reference herein to any specific commercial product, process, or service by trade name, trademark, manufacturer, or otherwise, does not necessarily constitute or imply its endorsement, recommendation, or favoring by the United States Government or the University of California. The views and opinions of authors expressed herein do not necessarily state or reflect those of the United States Government or the University of California and shall not be used for advertising or product endorsement purposes.

This work was supported by the United States Nuclear Regulatory commission under a Memorandum of Understanding with the United States Department of Energy, and performed under the auspices of the U.S. Department of Energy by Lawrence Livermore National Laboratory under Contract W-7405-Eng-48. 


\section{Lawrence Livermore National Laboratory Probabilistic Seismic Hazard Codes Validation}

Prepared by

J. B. Savy

September 8, 2003

Prepared for

Division of Research Engineering and Safety Office of Nuclear Regulatory Research U.S. Nuclear Regulatory Commission Washington, DC 20555 


\begin{abstract}
Probabilistic Seismic Hazard Analysis (PSHA) is a methodology that estimates the likelihood that various levels of earthquake-caused ground motion will be exceeded at a given location in a given future time-period. LLNL has been developing the methodology and codes in support of the Nuclear Regulatory Commission (NRC) needs for reviews of site licensing of nuclear power plants, since 1978. A number of existing computer codes have been validated and still can lead to ranges of hazard estimates in some cases. Until now, the seismic hazard community had not agreed on any specific method for evaluation of these codes.

The Earthquake Engineering Research Institute (EERI) and the Pacific Engineering Earthquake Research (PEER) center organized an exercise in testing of existing codes with the aim of developing a series of standard tests that future developers could use to evaluate and calibrate their own codes. Seven code developers participated in the exercise, on a voluntary basis. Lawrence Livermore National laboratory participated with some support from the NRC. The final product of the study will include a series of criteria for judging of the validity of the results provided by a computer code.

This EERI/PEER project was first planned to be completed by June of 2003. As the group neared completion of the tests, the managing team decided that new tests were necessary. As a result, the present report documents only the work performed to this point. It demonstrates that the computer codes developed by LLNL perform all calculations correctly and as intended. Differences exist between the results of the codes tested, that are attributed to a series of assumptions, on the parameters and models, that the developers had to make. The managing team is planning a new series of tests to help in reaching a consensus on these assumptions.
\end{abstract}




\section{TABLE OF CONTENTS}

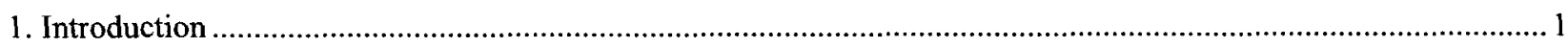

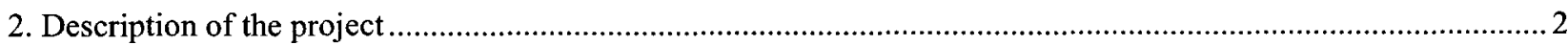

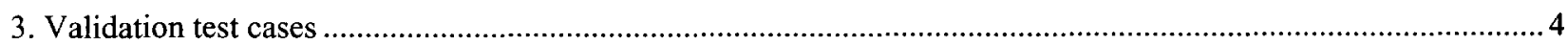

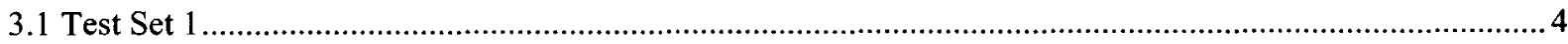

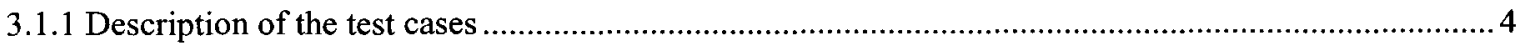

3.1.2 Cases 1a - 1 g

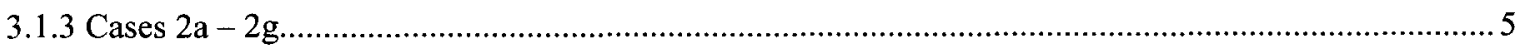

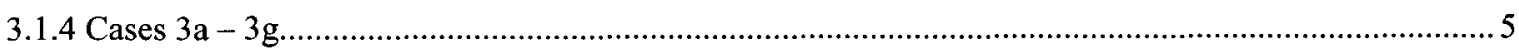

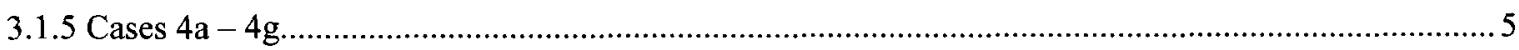

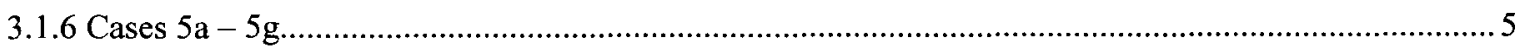

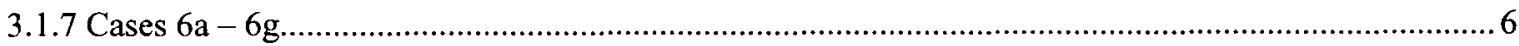

3.1.8 Cases 7a-7g

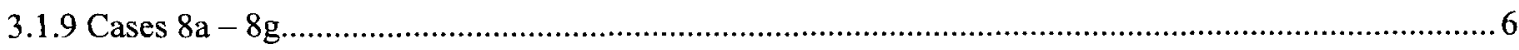

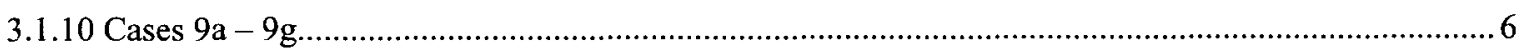

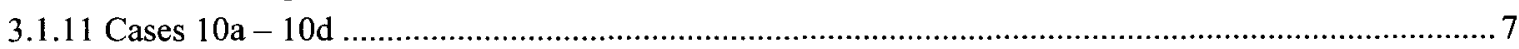

3.1.12 Cases $11 \mathrm{a}-11 \mathrm{~d}$

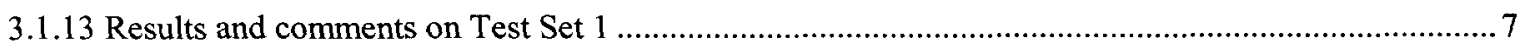

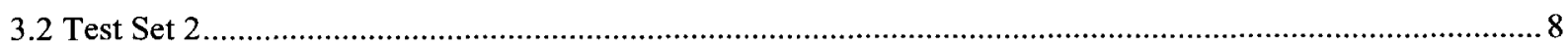

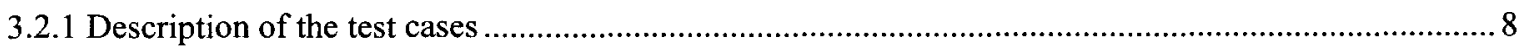

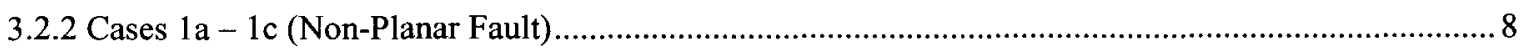

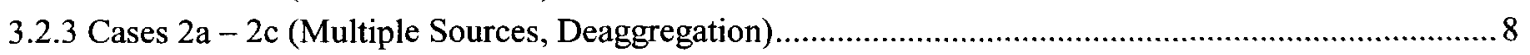

3.2.4 Cases $3 \mathrm{a}-3 \mathrm{c}$ (Recurrence Interval, Characteristic Model) ……....................................................... 9

3.2.5 Cases $4 a-4 c$ (Recurrence Interval, Truncated Normal Model) ................................................... 9

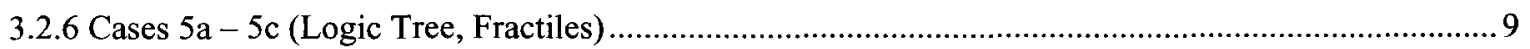

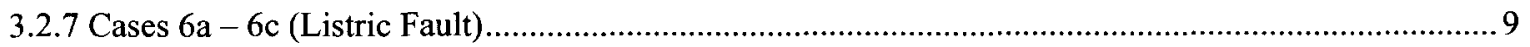

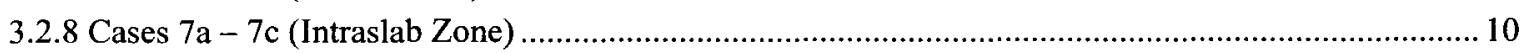

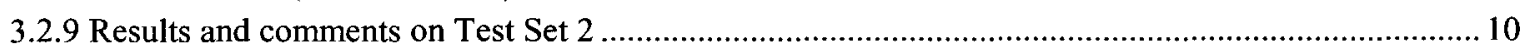

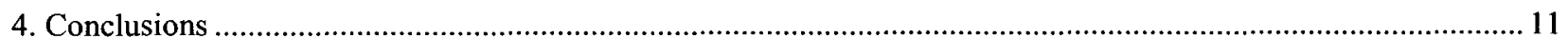




\section{FIGURES}

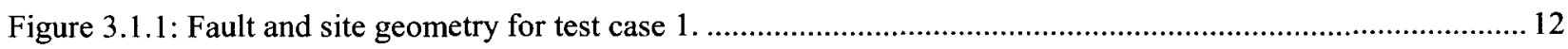

Figure 3.1.2: Truncated Normal Magnitude Density Function ........................................................................ 13

Figure 3.1.3: Characteristic Magnitude Density Function (Youngs \& Coppersmith, 1985)...................................... 13

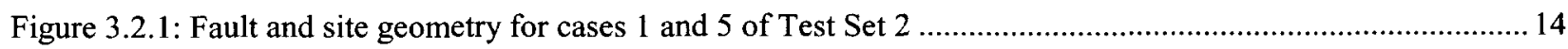

Figure 3.2.2: Fault and site coordinates for case 2 of Test Set 2 ................................................................... 14

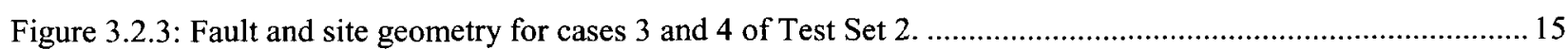

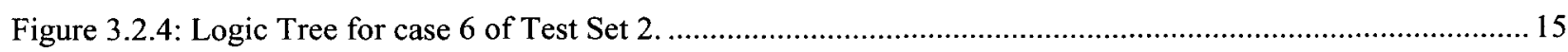

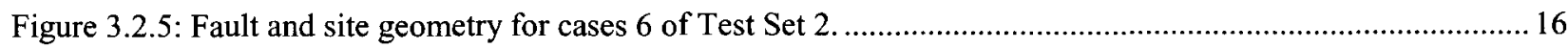

Figure 3.2.6:Intraslab zone and site geometry for case 7 of Test Set 2. .......................................................... 16

Figure 3.2.7: 3D Simulation of events on the 5-segments Fault A, showing the 3D intersections of the planar

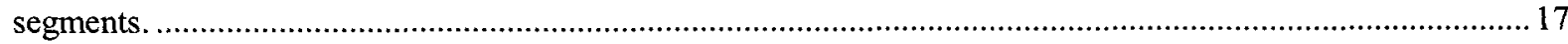

Figure 3.2.8: 3D simulation of a 65.5 Magnitude rupture partially on two segments of the listric Fault of case $6 \ldots . . .17$

Figure 3.2.9: 3D simulation of a 6.8 Magnitude rupture partially on two segments of the listric Fault of case $6 \ldots . . . . .18$ 


\section{ACKNOWLEDGMENTS}

The U.S. Nuclear Regulatory Commission (NRC) has sponsored this project. The project manager for the NRC was Dr. Andrew Murphy, and Dr. Jean Savy was the project manager for Lawrence Livermore National Laboratory. 


\section{Introduction}

Probabilistic seismic hazard analysis (PSHA) based on the Cornell model (Cornell, 1968) has become the preferred approach for assessing the ground-shaking hazard at sites of important and critical facilities and on a regional scale for the purposes of defining seismic design levels for building codes. The approach was first developed by Cornell in 1968 and was followed by a publicly available code (McGuire, 1978). Since then, numerous individual practitioners have developed PSHA codes and several have been made publicly available.

As seismic source characterization of active faults and area sources has advanced and our knowledge has become more detailed in terms of source geometry and earthquake recurrence, the codes have become more sophisticated.

The Earthquake Engineering Research Institute (EERI), in conjunction with the Pacific Earthquake Engineering Research center (PEER) have embarked in providing a forum for comparing the PSHA codes, those publicly available as well as others whose developers have volunteered to participate in the exercise.

The project tested both publicly available codes as well as proprietary codes that have been used extensively in the hazard evaluation of some of the most critical facilities in the U.S. The focus of this evaluation was numerical verification of the codes and analysis and comparison of their various features. The hazard calculations for area and planar fault sources, the magnitude density functions, attenuation relationships, and the normal probability integral are some of the items that will be analyzed in each code. In addition, a survey of practitioners on some of the key assumptions they make in PSHA (e.g. how much uncertainty in ground motion attenuation is included in their PSHA 's or how is the "characteristic" model simulated) was performed.

The codes used in the licensing of nuclear power plants of the 1980s' have been subjected to much scrutiny. The code used by the Nuclear power utilities, developed by the Electric Power 
Research Institute (EPRI), and finalized in 1989 was extensively tested and validated at a cost of more than $3 / 4$ million dollars, in 1989. Similarly, the NRC code, developed by LLNL and used for the PSHA estimates of 1989 and for the update of 1993 was extensively tested by LLNL. A special project funded by NRC RES and EPRI in 1989 compared the two codes by analyzing the results of a number of test cases, thus validating in effect the two codes simultaneously.

Since then the LLNL codes have evolved in a series of upgrades, the latest of which has been the transfer to a PC based operating system. LLNL has performed numerous checks and internal validations without fully validating its codes in a manner similar to that of the EPRI code. The exercise presented herein gave the NRC an exceptional opportunity to validate the latest LLNL codes, designed for being used by the NRC staff, at a fraction of the cost of doing a full fledge QA exercise.

\section{Description of the project}

The EERI validation project, managed by URS, in Oakland California used 18 test cases, which ranged from the simplest to more sophisticated. These test cases were provided to each of the participants and they in turn provided the results. A schedule was established based on discussions with the participants and all efforts were made to maintain that schedule. The product of this EERI/URS effort will be a final report, that will describe the project, its approach, and compare and evaluate the results of each of the codes. The test cases and their results established as part of this project will be entered on the PEER website to allow other interested parties to evaluate the codes. The publicly available codes that URS tested are EZFRISK developed by Risk Engineering, Inc., HAZ31 by Norm Abrahamson, and FRISK- by Tom Blake.

Other codes include:

U.S. Bureau of Reclamation : Jon Ake/Roland La Forge

United States Geological Survey : Edward Field (Los Angeles)

Impact Forecasting : Andres Mendez

United States Geological Survey: Mark Peterson (Denver)

URS Corporation : Phalkun Tan

Geomatrix Consultants : Bob Youngs

Risk Engineering, Inc. : Gabriel Toro and Robin Mc Guire 
New Zealand Institute of Geological and Nuclear Sciences : Mark Stirling

The objective of the NRC project was to provide the NRC with a suite of PSHA codes that will have been validated in the EERI/PEER exercise. The results of existing LLNL suite of codes were compared with those of other existing codes and to analytical results. This validated the numerical results, confirmed the validity of the algorithms, and procedures used in the calculations of the seismic hazard.

Another purpose of the project was to agree on a set of proven numerical algorithms and procedures based upon a consensus among the scientific and engineering community of PSHA practitioners. Since a number of procedures have been developed over the years, without consultation between the various researchers, the validation group selected a number of agreed upon practices, thereby setting standards. This required changes in some of the codes, and the developer performed the changes, to the extent that they did not require major reprogramming of the codes.

LLNL fully participated in the elaboration of the EERI project by contributing to the actual definition of the test cases and of the final product of the project.

We participated in several workshops, the purpose which was to analyze in detail the methodologies of each of the codes and generate interaction between the developers. LLNL prepared for those workshops, providing results for the test cases and any additional sensitivity cases that were necessary to understand the details of the codes.

The overall schedule and definition of the tasks in this project is determined by the structure of the EERI/URS project that is articulated in a series of (a) test cases definition workshops, (b) calculation runs, (c) evaluation meetings and finally, (d) updates and modifications by the codes' developers, to converge towards a common set of practices.

The main tasks of this project were as follows:

- Development of the Test Cases, run test cases, and evaluation of the results

- Perform minor changes to the codes if necessary 
- Write a report documenting the validation process

\section{Validation test cases}

\subsection{Test Set 1}

\subsubsection{Description of the test cases}

The following describes the first set of test cases. Figure 3.1.1 illustrates the fault and site geometry. Provide hazard results (probability of exceedance) for peak horizontal acceleration and $1.0 \mathrm{sec}$ spectral acceleration defined at $0.001,0.01,0.05,0.1,0.15,0.2,0.25,0.3,0.4,0.5,0.6$, $0.7,0.8,0.9,1.0,1.1,1.2,1.3,1.4$, and $1.5 \mathrm{~g}$. Assume a Poisson model when converting rates to probabilities.

For all cases:

Minimum Magnitude $=5.0$

Magnitude Step Size: 0.01 magnitude units for Cases 1a-1g, 0.1 magnitude units for all others Horizontal and Vertical Integration Step Size: $1 \mathrm{~km}$

Rupture dimension relationships:

$$
\begin{array}{ll}
\log (A)=M-4 & \sigma A=0.25 \\
\log (W)=0.5^{*} M-2.15 & \sigma W=0.15 \\
\log (L)=0.5^{*} M-1.85 & \sigma L=0.20
\end{array}
$$

Aspect Ratio $=2$

The Sigma value for all rupture dimension relationships is set to zero for all cases except $3 a-3 g$. For all faults, slip-rate $=2 \mathrm{~mm} /$ year, $\mathrm{b}$-value $=0.9$

For area source, number of events per year of minimum magnitude and greater $(\mathrm{Mw} \geq 5)$ is 0.0395 for the whole area, and $M \max =61 / 2$. 


\subsubsection{Cases $1 \mathrm{a}-1 \mathrm{~g}$}

Single magnitude event $(\mathrm{Mw}=6.5)$ on Fault 1 , as described in Figure 3.1.1, that ruptures entire fault plane. Use Boore et al. (1997), average shear velocity in upper $30 \mathrm{~m}=1070 \mathrm{~m} / \mathrm{sec}$, sigma $=$ 0 . Specify how moment is calculated in your code and what value is used for shear modulus. Calculate hazard for the seven sites shown on Figure 3.3.1 $(1 \mathrm{a}=$ site $1,1 \mathrm{~b}=$ site $2,1 \mathrm{c}=$ site $3 \ldots$ $1 \mathrm{~g}=$ site 7$)$.

\subsubsection{Cases $2 a-2 g$}

Single magnitude event $(\mathrm{Mw}=6.0)$ on Fault 1 with one size rupture plane (smaller than total fault plane area) as defined using the rupture area (RA), rupture width (RW), rupture length (RL) and/or aspect ratio relationships given below $(\sigma \mathrm{RA}=\sigma \mathrm{RL}=\sigma \mathrm{RW}=0)$. Use Boore et al. (1997), average shear velocity in upper $30 \mathrm{~m}=1070 \mathrm{~m} / \mathrm{sec}$, sigma $=0$. Specify how moment is calculated in the code and what value is used for shear modulus. Calculate hazard for the seven sites shown on Figure 3.1.1 $(2 \mathrm{a}=$ site $1,2 \mathrm{~b}=$ site $2,2 \mathrm{c}=$ site $3 \ldots 2 \mathrm{~g}=$ site 7$)$.

\subsubsection{Cases $3 a-3 g$}

Single magnitude event $(M w=6.0)$ on Fault 1 with rupture planes as defined using the $R A, R W$, $\mathrm{RL}$ and/or aspect ratio relationships given below (include sigma in these relationships). Use Boore et al. (1997), average shear velocity in upper $30 \mathrm{~m}=1070 \mathrm{~m} / \mathrm{sec}$, sigma $=0$. Specify how moment is calculated in your code and what value is used for shear modulus. Calculate hazard for the seven sites shown on Figure 3.1.1 ( $3 \mathrm{a}=$ site $1,3 \mathrm{~b}=$ site $2,3 \mathrm{c}=$ site $3 \ldots 3 \mathrm{~g}=$ site 7$)$.

\subsubsection{Cases $4 a-4 g$}

Single magnitude event $(\mathrm{Mw}=6.0)$ on Fault 2, as described in Figure 3.1.1, with one size rupture plane (smaller than total fault plane area) as defined using the RA, RW, RL and/or aspect ratio relationships given below $(\sigma \mathrm{RA}=\sigma \mathrm{RL}=\sigma \mathrm{RW}=0)$. Use Boore et al. (1997), average shear velocity in upper $30 \mathrm{~m}=1070 \mathrm{~m} / \mathrm{sec}$, sigma $=0$. Specify how moment is calculated in your code and what value is used for shear modulus. Calculate hazard for the seven sites shown on Figure 3.1.1 $(4 \mathrm{a}=$ site $1,4 \mathrm{~b}=$ site $2,4 \mathrm{c}=$ site $3 \ldots 4 \mathrm{~g}=$ site 7$)$.

\subsubsection{Cases $5 \mathrm{a}-5 \mathrm{~g}$}

Calculate hazard for all 7 sites due to rupture of Fault 1 of Figure 3.1.1, using the truncated exponential model $(\mathrm{Mmax}=6.7)$ and Boore et al. $(1997)$, average shear velocity in upper $30 \mathrm{~m}=$ 
$1070 \mathrm{~m} / \mathrm{sec}$, sigma $=0$. Use the RA, RW, and RL relationships (with $\sigma \mathrm{RA}=\sigma \mathrm{RL}=\sigma \mathrm{RW}=0$ ) to define dimensions of rupture planes.

\subsubsection{Cases $6 a-6 g$}

Calculate hazard for all 7 sites due to rupture of Fault 1 of Figure 3.1.1, using the truncated normal model $($ Mchar $=6.7, \mathrm{Mmax}=7.2$, sigma $=0.25$, see Figure 3.1.2) and Boore et al. (1997), average shear velocity in upper $30 \mathrm{~m}=1070 \mathrm{~m} / \mathrm{sec}$, sigma $=0$. Use the RA, RW, and RL relationships (with $\sigma \mathrm{RA}=\sigma \mathrm{RL}=\sigma \mathrm{RW}=0$ ) to define dimensions of rupture planes.

\subsubsection{Cases $7 \mathrm{a}-7 \mathrm{~g}$}

Calculate hazard for all 7 sites due to rupture of Fault 1 of Figure 3.1.1, using the characteristic model (Youngs \& Coppersmith [1985] $\mathrm{Mchar}=6.7, \mathrm{Mmax}=6.95$, see Figure 3.1.3) and Boore et al. (1997), average shear velocity in upper $30 \mathrm{~m}=1070 \mathrm{~m} / \mathrm{sec}$, sigma $=0$. Use the RA, RW, and $\mathrm{RL}$ relationships (with $\sigma \mathrm{RA}=\sigma \mathrm{RL}=\sigma \mathrm{RW}=0$ ) to define dimensions of rupture planes.

\subsubsection{Cases $8 \mathrm{a}-8 \mathrm{~g}$}

Calculate hazard for all 7 sites due to a single magnitude event $(\mathrm{Mw}=6.0)$ on Fault 1 of Figure 3.1 .1 , using Boore et al. (1997), average shear velocity in upper $30 \mathrm{~m}=1070 \mathrm{~m} / \mathrm{sec}$, sigma untruncated and truncated at 2 and 3 standard deviations. Use the RA, RW, and RL relationships (with $\sigma \mathrm{RA}=\sigma \mathrm{RL}=\sigma \mathrm{RW}=0$ ) to define dimensions of rupture planes.

\subsubsection{Cases $9 \mathrm{a}-9 \mathrm{~g}$}

Calculate hazard for all 7 sites due to a single magnitude event $(\mathrm{Mw}=6.0)$ on Fault 2 of Figure 3.1.1, using the following three attenuation relationships, all with sigma truncated at 3 standard deviations:

Boore et al. (1997), average shear velocity in upper $30 \mathrm{~m}=1070 \mathrm{~m} / \mathrm{sec}$

Abrahamson \& Silva (1997), rock

Campbell (1997), soft rock, depth to basement rock $=2 \mathrm{~km}$, depth to seismogenic zone $=$ $3 \mathrm{~km}$

Compute results for attenuation relationships individually. Use the RA, RW, and RL relationships (with $\sigma \mathrm{RA}=\sigma \mathrm{RL}=\sigma \mathrm{RW}=0$ ) to define dimensions of rupture planes. 


\subsubsection{Cases 10a-10d}

Calculate hazard at four sites for the area source defined in Figure 3.1.1 $(10 \mathrm{a}=$ site $1,10 \mathrm{~b}=$ site $2,10 \mathrm{c}=$ site $3,10 \mathrm{~d}=$ site 4$)$. Use truncated exponential model with $\mathrm{Mmax}=6.5$. Source should be uniformly distributed across the area $(1 \mathrm{~km}$ grid spacing) at a fixed depth of $5 \mathrm{~km}$. Attenuation relationship is Boore et al. (1997), average shear velocity in upper $30 \mathrm{~m}=1070 \mathrm{~m} / \mathrm{sec}$, sigma $=0$.

\subsubsection{Cases $11 \mathrm{a}-11 \mathrm{~d}$}

Calculate hazard at four sites for area source defined in Figure 3.3.1 $(11 \mathrm{a}=$ site $1,11 \mathrm{~b}=$ site 2, $11 \mathrm{c}=$ site $3,11 \mathrm{~d}=$ site 4). Use truncated exponential model with $\mathrm{Mmax}=6.5$. Source should be uniformly distributed (1 km grid spacing) throughout the volume defined by the area and a depth range of 5 to $10 \mathrm{~km}$. Attenuation relationship is Boore et al. (1997), average shear velocity in upper $30 \mathrm{~m}=1070 \mathrm{~m} / \mathrm{sec}$, sigma $=0$.

\subsubsection{Results and comments on Test Set 1}

None of the codes tested had the ability to easily model single magnitude earthquake sources, and most did not handle specific probability distributions as required in the test.

We modified our codes to handle easily all those cases, including giving the options of selecting the characteristic magnitude distribution density with rate input, or with total number of events. We also created this option for the truncated exponential model.

For the normal probability density function of magnitude, we used the existing option of inputting manually the density values.

For case 11 dealing with volume sources, we created the option of defining volume sources. They are essentially area sources at depth, with a range of elevations where earthquakes can occur. This option was also used in case 7 of Test Set 2 for the Intraslab source zone.

Overall Test Set 1, required substantial efforts for tuning the input and making many small modifications to the codes to be able to perform the tests, due to the fact that the tests were not representative of the type of calculations that are normally performed in standard PSHA. After 2 workshop that were conceived to review the preliminary results of the developers, most differences in assumptions and methods seemed to be understood and everybody was given the opportunity to revise their results one more time. The final evaluation and plots will be presented in the final EERI/PEER report 


\subsection{Test Set 2}

\subsubsection{Description of the test cases}

The following describes the second set of test cases. Provide mean hazard results (probability of exceedance) for peak horizontal acceleration and $1.0 \mathrm{sec}$ spectral acceleration defined at 0.001 , $0.01,0.05,0.1,0.2,0.3,0.4,0.5,0.75,1.0,1.25$, and $1.5 \mathrm{~g}$. Assume a Poisson model when converting rates to probabilities

For all cases:

Fault Rupture dimension relationships:

$$
\begin{array}{ll}
\log (\mathrm{A})=\mathrm{M}-4 & \sigma \mathrm{A}=0 \\
\log (\mathrm{W})=0.5^{*} \mathrm{M}-2.15 & \sigma \mathrm{W}=0 \\
\log (\mathrm{L})=0.5^{*} \mathrm{M}-1.85 & \sigma \mathrm{L}=0 \\
\text { Aspect Ratio }=2 &
\end{array}
$$

\subsubsection{Cases 1a-1c (Non-Planar Fault)}

Calculate the hazard at the 3 sites shown on Figure 3.2.1 due to rupture of Fault A (unsegmented rupture only) using the truncated exponential model $(\mathrm{Mmax}=7.2)$, slip rate $=2 \mathrm{~mm} / \mathrm{yr}, \mathrm{b}$-value $=$ 0.9, and the Sadigh et al. (1997) attenuation relationship, rock, sigma $=0$. Use the RA, RW, and $\mathrm{RL}$ relationships given below (with $\sigma \mathrm{RA}=\sigma \mathrm{RL}=\sigma \mathrm{RW}=0$ ) to define dimensions of rupture planes. For integration, use a Mmin of 5.0 with a 0.1 step size.

\subsubsection{Cases 2a - 2c (Multiple Sources, Deaggregation)}

Calculate the hazard at the 3 sites shown on Figure 3.2.2 due to the area source, Fault B, and Fault C. For the area source, use the truncated exponential model $(M \max =6.5)$ and the cumulative number of events with $M \geq 5.0=0.0395$. For Fault $B(L=75 \mathrm{~km})$, use the characteristic model (Youngs \& Coppersmith [1985]; Mchar = 7.0, Mmax =7.25) and slip rate = $2 \mathrm{~mm} / \mathrm{yr}$. For Fault C ( $\mathrm{L}=25 \mathrm{~km}$ ), use the characteristic model (Youngs \& Coppersmith [1985]; Mchar $=6.5, \mathrm{Mmax}=6.75)$ and slip rate $=1 \mathrm{~mm} / \mathrm{yr}$. For all sources, use the Sadigh et al. (1997) attenuation relationship, rock, sigma $=0, \mathrm{~b}$-value $=0.9, \mathrm{Mmin}=5.0$, and magnitude integration step size $=0.1$. For the faults, use the RA, RW, and RL relationships given below (with $\sigma \mathrm{RA}=$ $\sigma \mathrm{RL}=\sigma \mathrm{RW}=0$ ) to define dimensions of rupture planes. 
Provide the following deaggregation results for peak ground acceleration and 1.0 second spectral acceleration at sites 1 and 3 corresponding to annual exceedance probabilities of 0.01 and 0.0001:

Modal values $M^{*}, D^{*}, \varepsilon^{*}$

Mean values $\mathrm{M}$-bar, D-bar, $\varepsilon$-bar

\subsubsection{Cases 3a - 3c (Recurrence Interval, Characteristic Model)}

Calculate hazard for all 3 sites due to rupture of Fault D (Figure 3.2.3) using the characteristic model (Youngs \& Coppersmith [1985]; Mchar $=6.2, \mathrm{Mmax}=6.45$ ), recurrence interval $=1000$ years, and the Sadigh et al. (1997) attenuation relationship, rock, sigma $=0$. Use the RA, RW, and $\mathrm{RL}$ relationships (with $\sigma \mathrm{RA}=\sigma \mathrm{RL}=\sigma \mathrm{RW}=0$ ) to define dimensions of rupture planes. For integration use a Mmin of 5.0 with a 0.1 step size.

\subsubsection{Cases 4a - 4c (Recurrence Interval, Truncated Normal Model)}

Calculate hazard for all 3 sites due to rupture of Fault D (Figure 3.2.3) using the truncated normal model $($ Mchar $=6.2, \mathrm{Mmax}=6.5$, sigma $=0.25)$, recurrence interval $=1000$ years, and the Sadigh et al. (1997) attenuation relationship, rock, sigma $=0$. Use the RA, RW, and RL relationships (with $\sigma \mathrm{RA}=\sigma \mathrm{RL}=\sigma \mathrm{RW}=0$ ) to define dimensions of rupture planes. For integration use $\mathrm{Mmin}=5.0$, with a 0.1 step size.

\subsubsection{Cases 5a - 5c (Logic Tree, Fractiles)}

Calculate hazard for all 3 sites due to rupture of Fault A (Figure 3.2.1) as shown in the logic tree on Figure 3.2.4. Provide the mean hazard along with the 5th and 95th percentile fractiles. Use the Sadigh et al. (1997) attenuation relationship, rock, sigma $=0$. Use the RA, RW, and RL relationships (with $\sigma \mathrm{RA}=\sigma \mathrm{RL}=\sigma \mathrm{RW}=0$ ) to define dimensions of rupture planes. For integration use a Mmin of 5.0 with a 0.1 step size.

\subsubsection{Cases 6a-6c (Listric Fault)}

Calculate hazard for all 3 sites due to rupture of Fault E (Figure 3.2.5) using the truncated exponential model $(\mathrm{Mmax}=6.5)$ and the Sadigh et al. (1997) attenuation relationship, rock, sigma $=0$. Assume the fault is strike-slip for the attenuation relationship. Use the RA, RW, and 
$\mathrm{RL}$ relationships (with $\sigma \mathrm{RA}=\sigma \mathrm{RL}=\sigma \mathrm{RW}=0$ ) to define dimensions of rupture planes. For integration use a Mmin of 5.0 with a 0.1 step size.

\subsubsection{Cases 7a - 7c (Intraslab Zone)}

Calculate hazard for all 3 sites due to rupture of the intraslab zone with uniform thickness of 10 $\mathrm{km}$ (Figure 3.2.6) using the truncated exponential model $(\mathrm{Mmax}=7.5)$ and the Youngs et al. (1997) attenuation relationship. For integration use a Mmin of 5.0 with a 0.1 step size.

\subsubsection{Results and comments on Test Set 2}

Test Set 2 was intended to test the 3D capabilities of the codes, as well as their ability to propagate the epistemic uncertainty into final hazard results.

The results and plot comparisons will be available in the final EERI/Peer report, when the results of the final workshop are made public.

The first calculations led to results that fell squarely in the middle of the group, with small differences in the near field and for very small values of the ground motion, therefore, of no great importance in actual calculations. The differences were analyzed and associated with the fact that our 3D faults were made of flat rectangular panelssegments that could overlap, or present gaps, when the trace of the fault is not a straight line. Although most codes make this same approximation, that leads to a small difference in the results, we modified our code to become fully 3D.

Our code now has the ability to handle, and visualize the $3 \mathrm{D}$ representation of the entire fault, as well as the 3D representation of all the individual simulations of magnitudedependent ruptures. Figure 3.2.7 shows one simulation for magnitude 6.0 of the 5segment Fault A whose trace is not a straight line and dip is 60 degrees. Figure 3.2 .8 and 3.2.9 show such simulations for magnitudes 5.5 and 6.8 on the listric fault 1 of case 6 , Test Set 2.

In the case of the Intraslab zone, we created a new option for selecting the depth of an area source, and providing for a thickness equal to the $10 \mathrm{~km}$ of the intraslab zone. However, since the intraslab zone was dipping, we discretized it into 25 
parallelepipedic volume zones at variable depth, following the average depth of the intraslab, and constant thickness, $10 \mathrm{~km}$.

\section{Conclusions}

The series of tests conducted on the PSHA computer codes developed by LLNL demonstrated that these codes produced the intended numerical results. During the performance of the tests, a number of features were added to the codes to be able to perform the tests which, in some instances required capabilities usually not required in professional PSHA calculations. This is, for example, the case of point sources, or single magnitude earthquake calculations, that were necessary to test the basic algorithms. In spite of the simplicity of the analytical formulation of the "PSHA equation", the tests showed that developers had to make many assumptions that potentially lead to different numerical results. These assumptions include:

- Discretization schemes, in space and in magnitudes,

- Values of standard parameters, conversions from magnitudes to moments, etc,

- Approximation methods of integration,

- Random generators,

- Selection of algorithms for approximation of tails of probability distributions,

- Representation of faults in 3 dimensions, and their rupture kinematics.

Consequently, the results from the computer codes selected in the project do present differences that, in some cases can be rather large, particularly when the tests exercise features of the codes that are not intended to be used, or when the calculations go into regions of the probability distributions that are not appropriate.

Realizing that the sources of genuine differences (aside from errors in programming or obvious errors in selections of models, or parameters) were more numerous and complex than first believed, the managing team decided to design a few more simple tests. These new tests will provide information on the respective importance of each of the identified differences in the codes, and will help in formulating recommendations, opting for a consensus of the group of testers whenever possible. 
FAULT 1

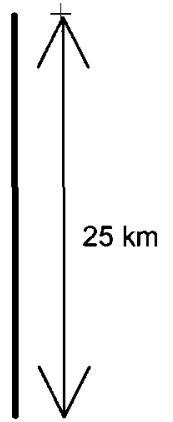

Fault Type: Strike Slip

Dip: 90 degrees

Fault Plane Depths: 0 - $12 \mathrm{~km}$
FAULT 2

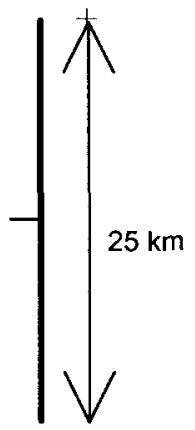

Fault Type: Reverse

Dip: 60 degrees west

Fault Plane Depths: 1 - $12 \mathrm{~km}$
SITES FOR FAULTS $1 \& 2$

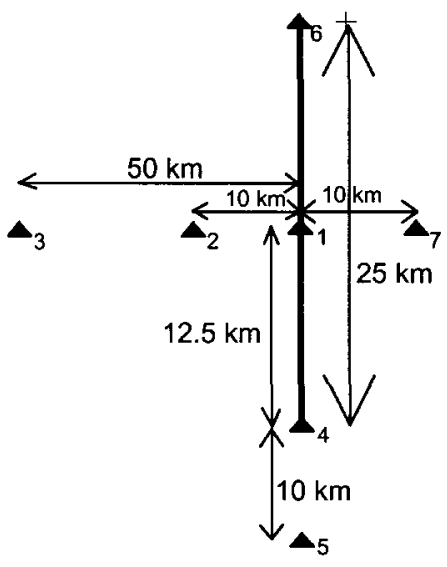

Site 1: On fault, at midpoint along strike

Site 2: $10 \mathrm{~km}$ west of fault, at midpoint along strike

Site 3: $50 \mathrm{~km}$ west of fault, at midpoint along strike

Site 4: On fault, at southern end

Site 5: $10 \mathrm{~km}$ south of fault along strike

Site 6: On fault, northern end

Site 7: $10 \mathrm{~km}$ east of fault, at midpoint along strike
AREA 1 WITH SITES

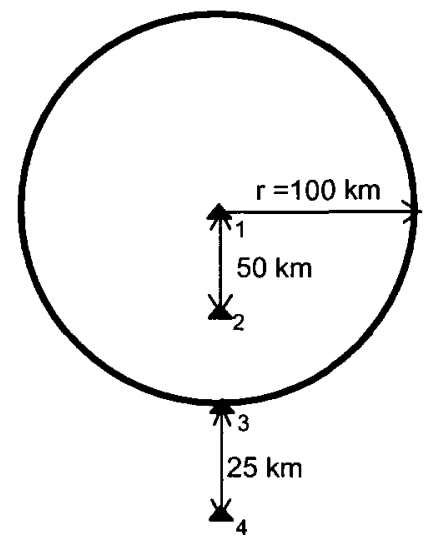

Site 1: At center of area

Site 2: $50 \mathrm{~km}$ from center (radially)

Site 3: On area boundary

Site 4: $25 \mathrm{~km}$ from boundary Site 1

Fault 2

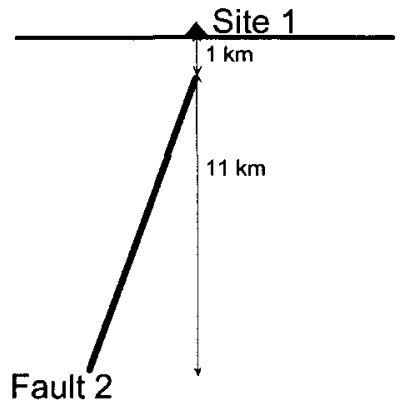




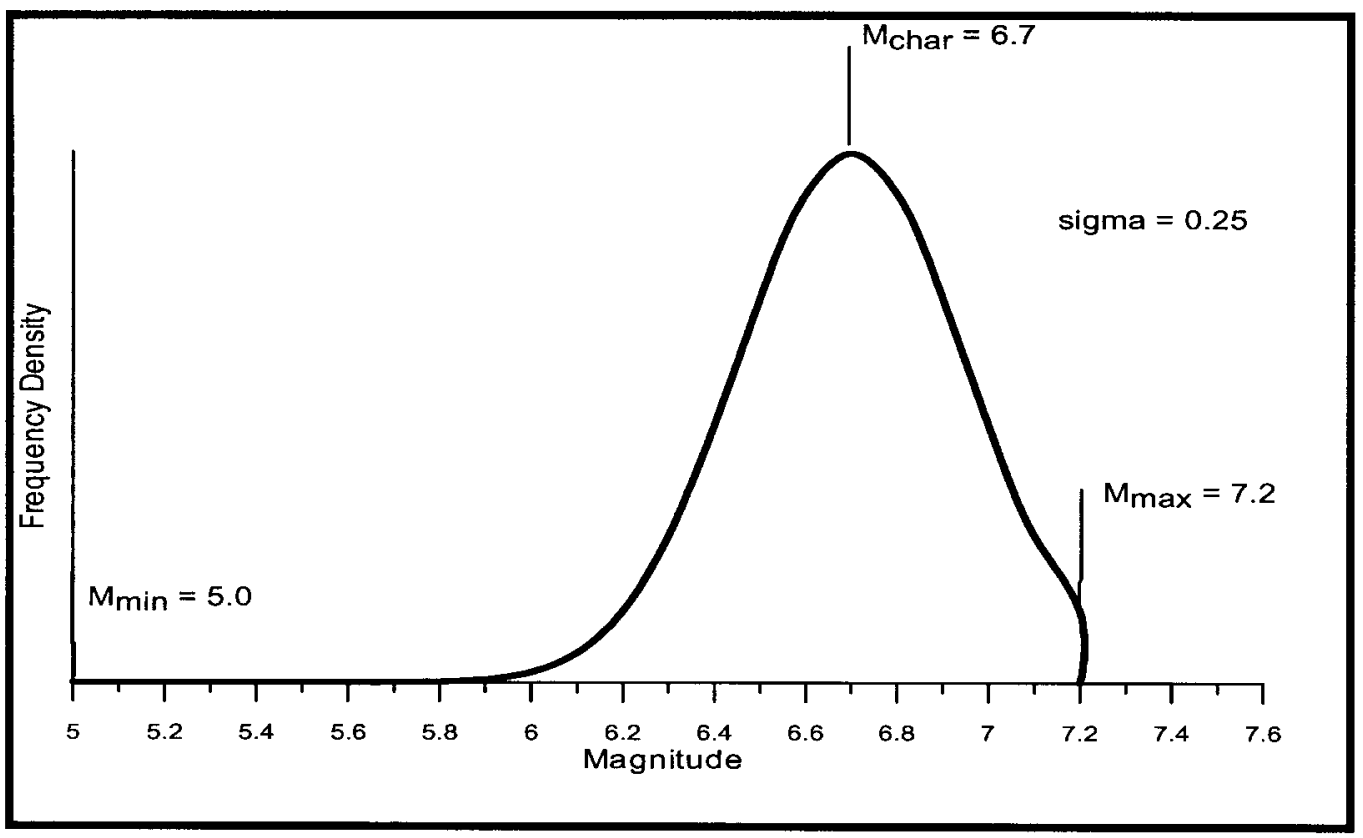

Figure 3.1.2: Truncated Normal Magnitude Density Function

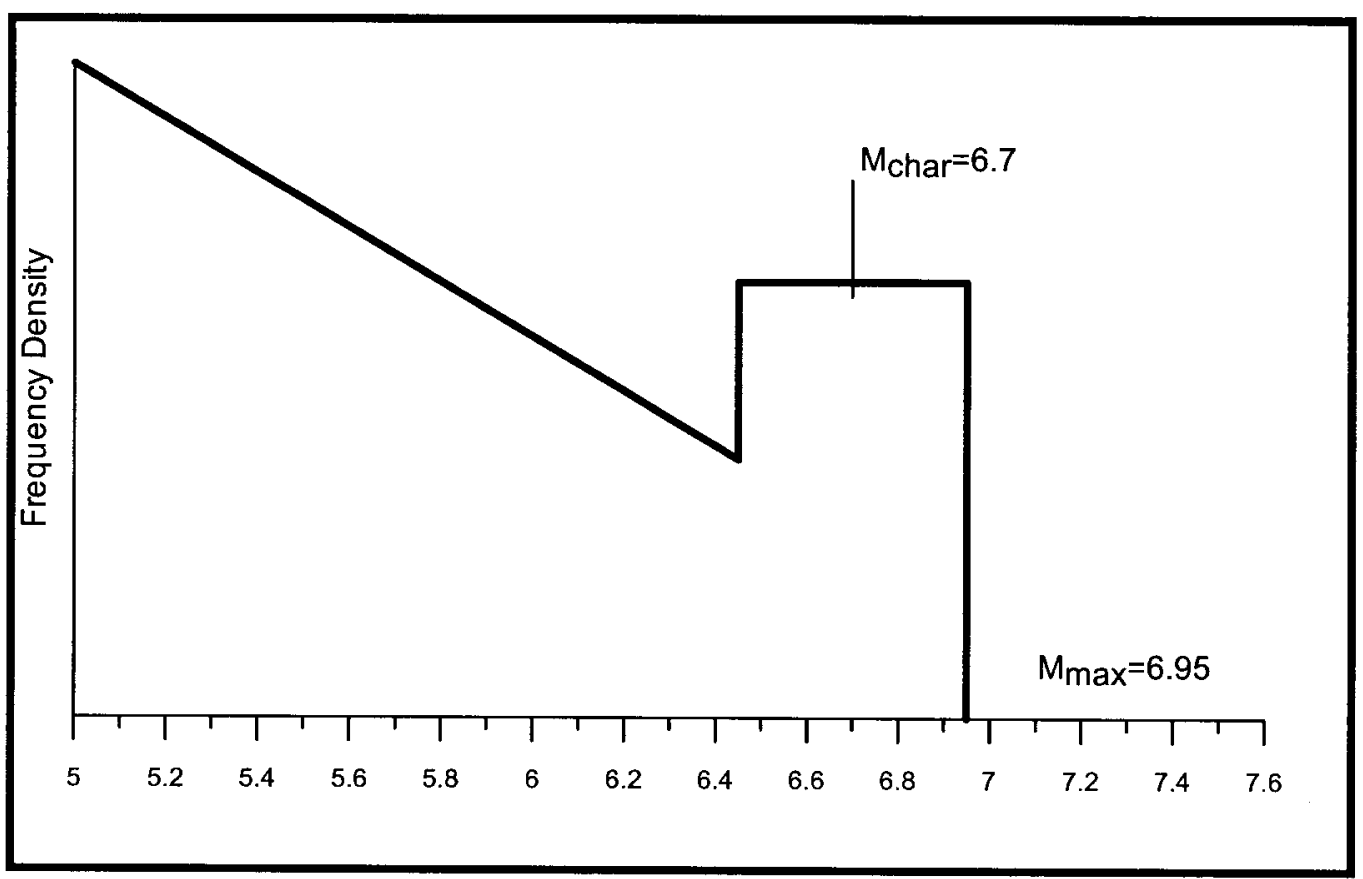

Figure 3.1.3: Characteristic Magnitude Density Function (Youngs \& Coppersmith, 1985) 


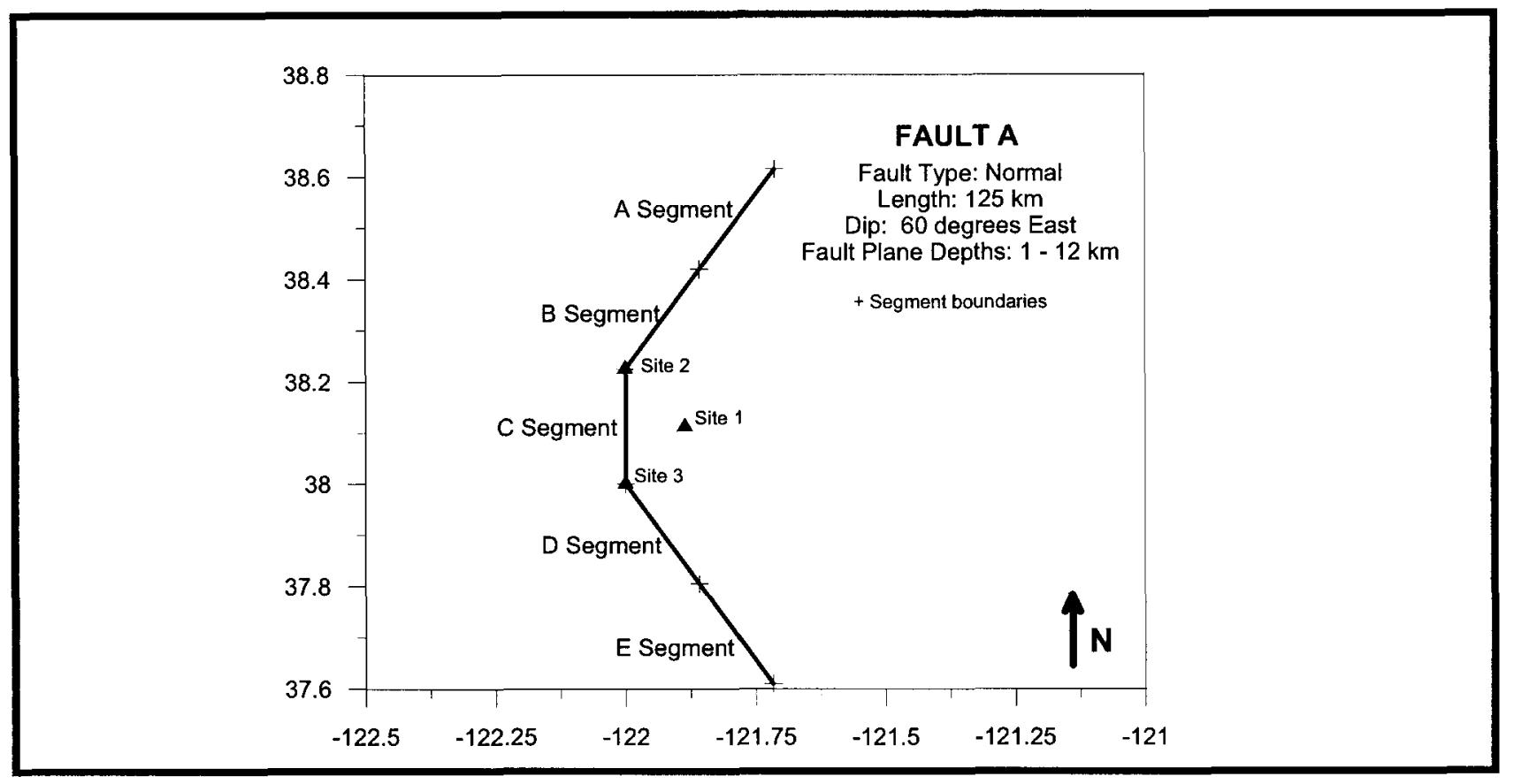

Figure 3.2.1: Fault and site geometry for cases 1 and 5 of Test Set 2

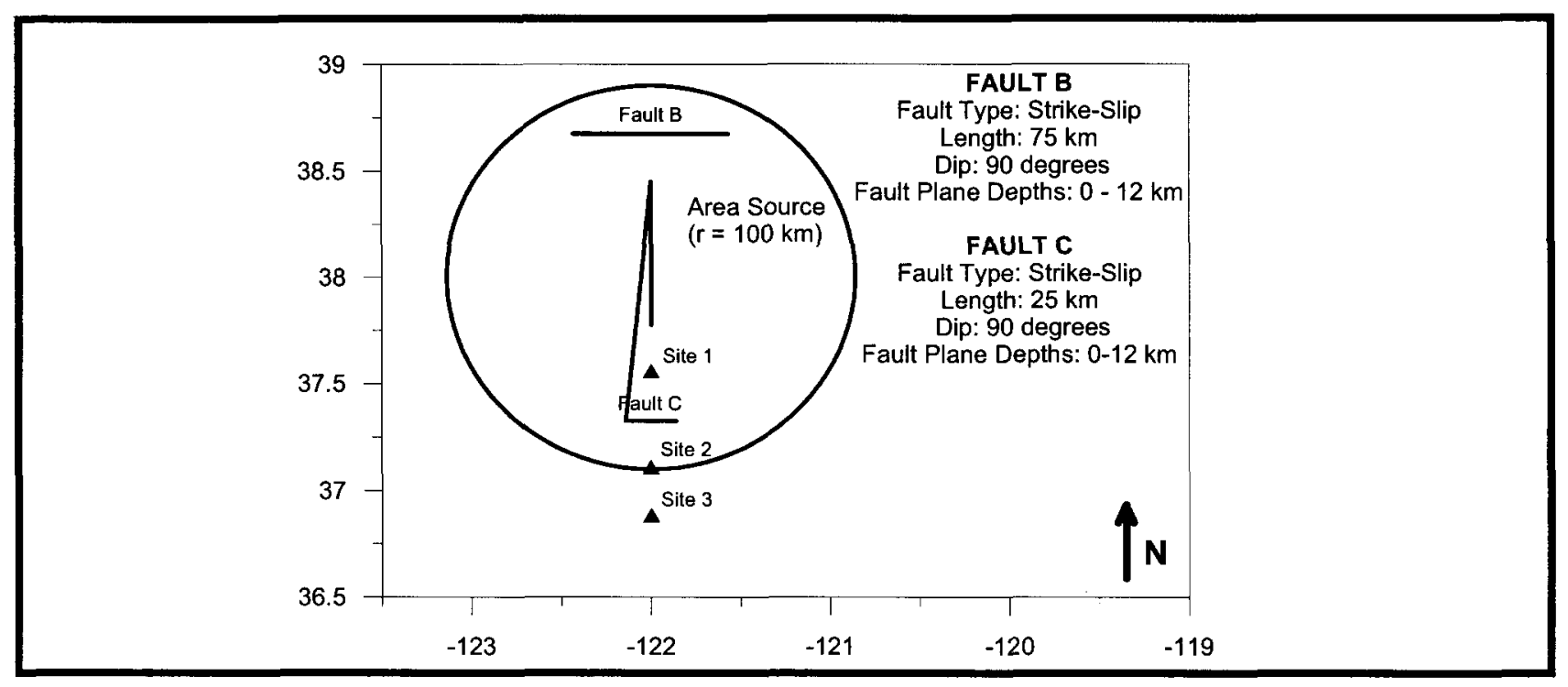

Figure 3.2.2: Fault and site coordinates for case 2 of Test Set 2. 


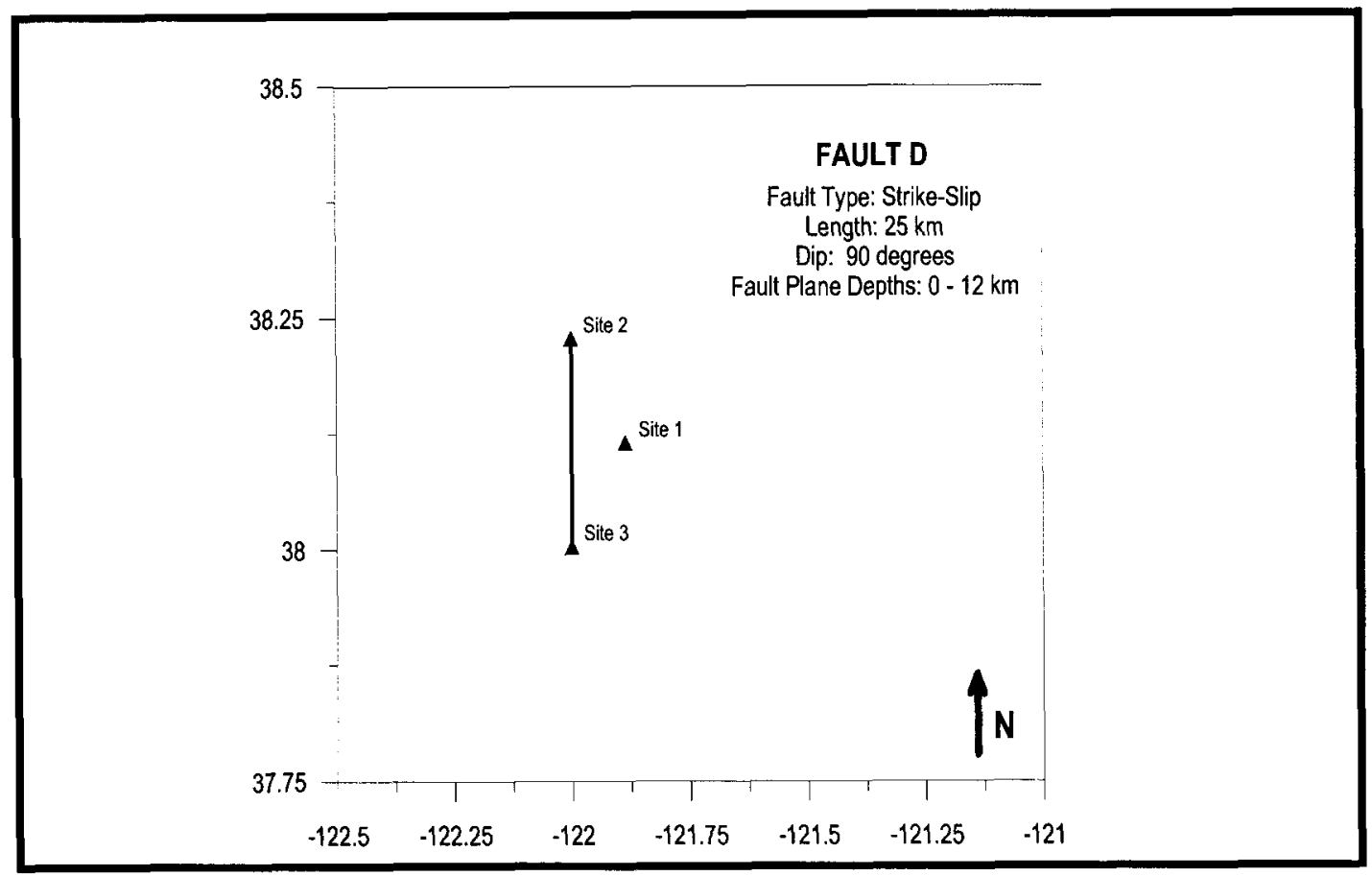

Figure 3.2.3: Fault and site geometry for cases 3 and 4 of Test Set 2.

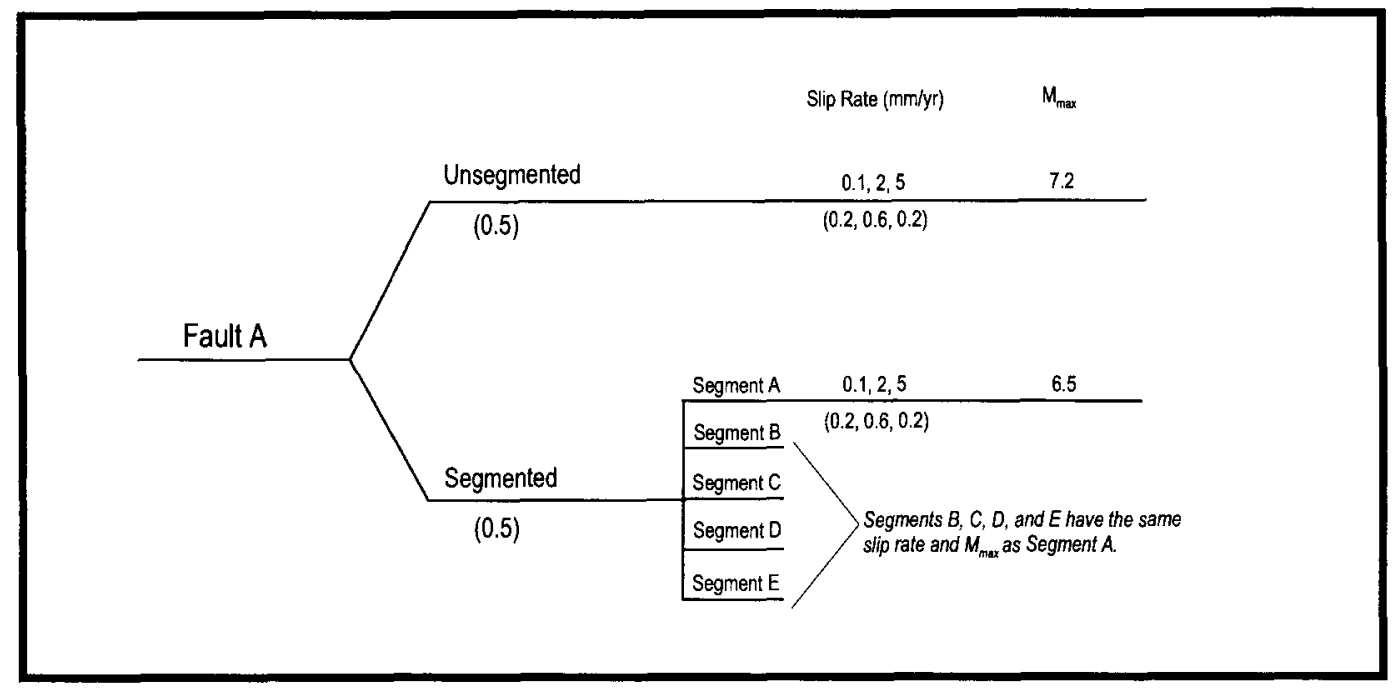

Figure 3.2.4: Logic Tree for case 6 of Test Set 2. 


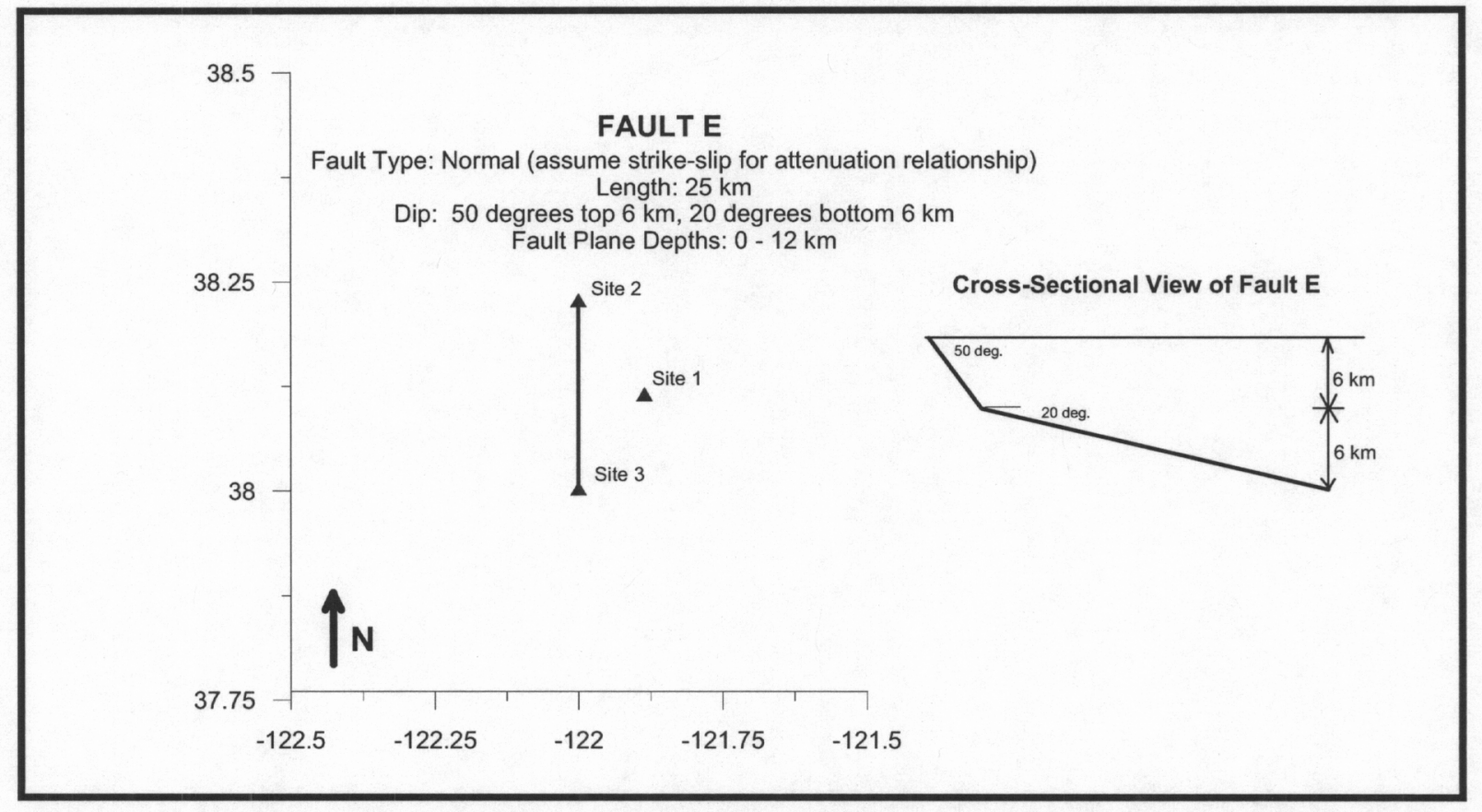

Figure 3.2.5: Fault and site geometry for cases 6 of Test Set 2 .

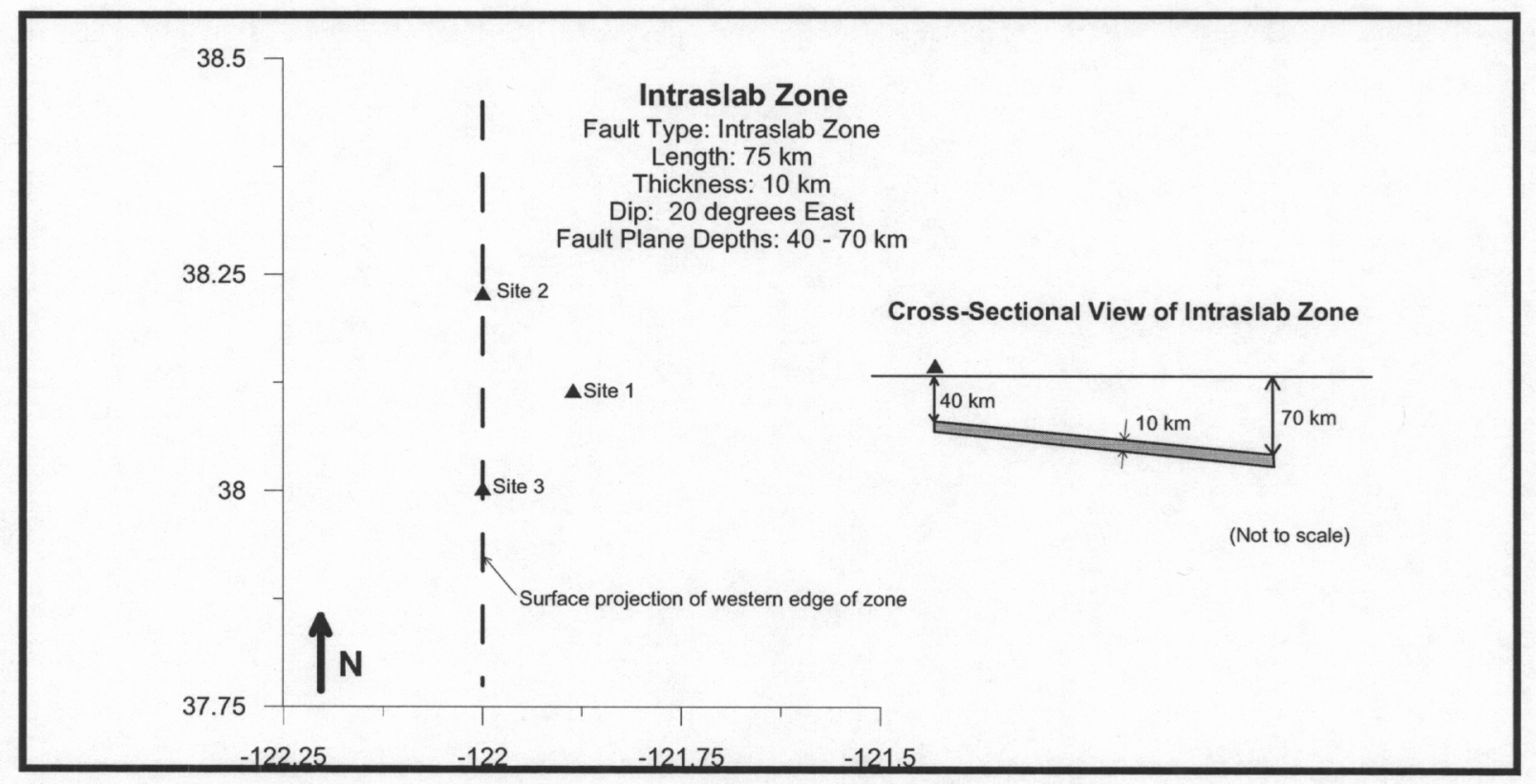

Figure 3.2.6:Intraslab zone and site geometry for case 7 of Test Set 2. 


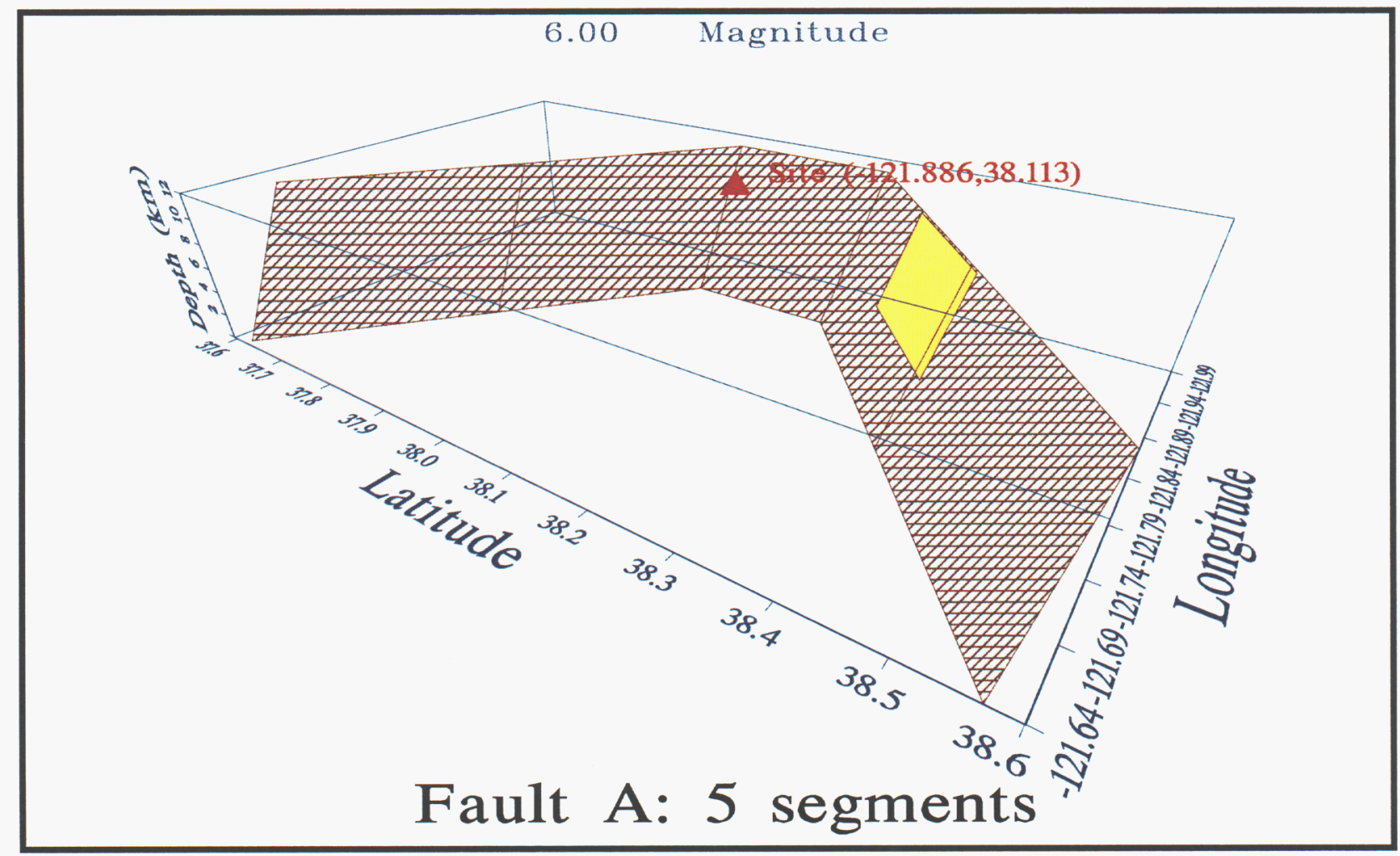

Figure 3.2.7: 3D Simulation of events on the 5-segments Fault A, showing the 3D intersections of the planar segments.

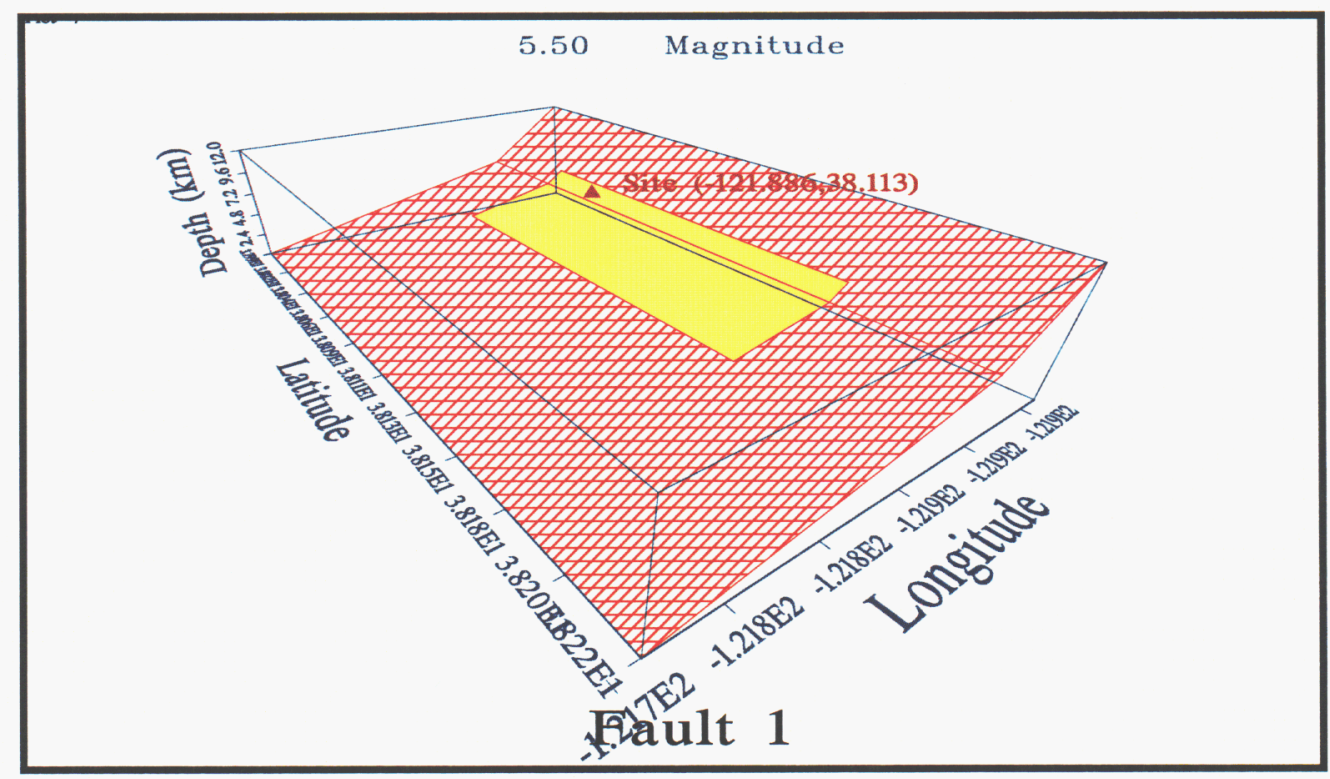

Figure 3.2.8: 3D simulation of a 65.5 Magnitude rupture partially on two segments of the listric Fault of case 6. 


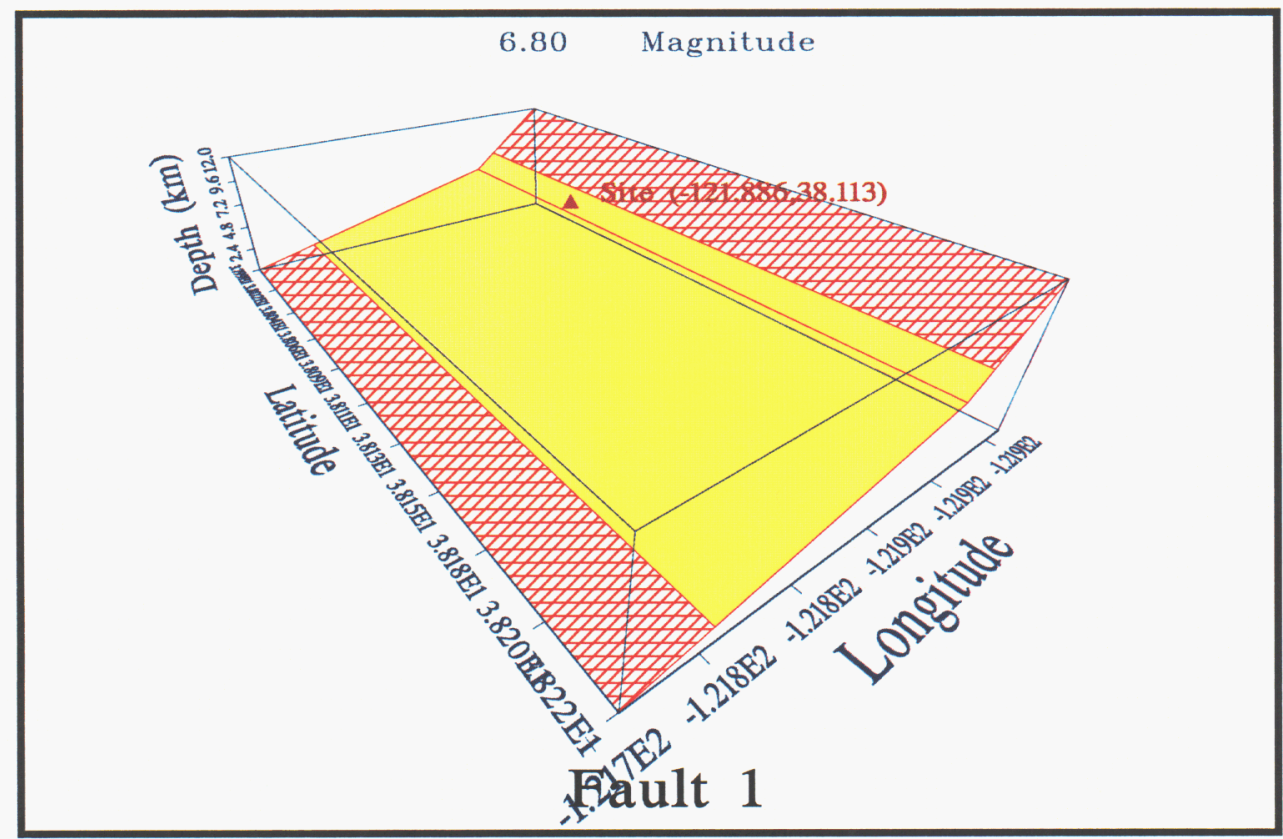

Figure 3.2.9: 3D simulation of a 6.8 Magnitude rupture partially on two segments of the listric Fault of case 6. 
